\title{
Cytokines as therapeutic targets for the gastrointestinal manifestations of scleroderma
}

\author{
Jennifer M Raoul BSc ${ }^{1}$, Monica Verma MSc ${ }^{1}$, Ernest Tan $\mathrm{BSc}^{1}$, Theresa C Peterson $\mathrm{PhD}^{1,2}$
}

\begin{abstract}
JM Raoul, M Verma, E Tan, TC Peterson. Cytokines as therapeutic targets for the gastrointestinal manifestations of scleroderma. Can J Gastroenterol 2004;18(1):22-24.

Systemic sclerosis (SSc), or scleroderma, is a connective tissue disorder characterized by progressive fibrosis of the skin and internal organs. It has significance for gastroenterologists because the gastrointestinal tract is involved in $90 \%$ of SSc patients, who often present with esophageal dysfunction. Though the exact pathogenesis of SSc is unknown, there is increasing evidence supporting an immune mechanism. Cytokines are the soluble mediators of immune activation, altered fibroblast proliferation and extracellular matrix accumulation in SSc and thereby provide important therapeutic targets. In the present review, the involvement of cytokines in SSc is discussed with particular emphasis on cytokines and growth factors that have been implicated in the disease process and likely play an important role in the gastrointestinal manifestations of scleroderma. The role of cytokines as therapeutic targets in scleroderma forms the basis of this timely review.
\end{abstract}

Key Words: CTGF; Cytokines; GI dysfunction; IL-4; IL-6; MCP-1; PDGF; Scleroderma; TGF- $\beta$

\section{Cytokines : cible thérapeutique des manifesta- tions gastro-intestinales de la sclérodermie}

La sclérodermie, ou sclérose généralisée, est une maladie du tissu conjonctif, qui se caractérise par une fibrose évolutive de la peau et des organes internes. L'affection revêt de l'importance pour les gastro-entérologues étant donné que le tube digestif est atteint dans $90 \%$ des cas et que les troubles s'accompagnent d'un dysfonctionnement de l'œsophage. Même si on ne connaît pas précisément la pathogenèse de la sclérodermie, de plus en plus de données permettent de croire à un mécanisme immunitaire. Les cytokines sont les médiateurs solubles de l'activation immunitaire, de la prolifération de fibroblastes anormaux et de l'accumulation de matrices extracellulaires observées dans la sclérodermie; ces médiateurs constituent donc une cible thérapeutique toute désignée. Il sera question, dans le présent article, de la participation des cytokines dans la sclérodermie, plus particulièrement des cytokines et des facteurs de croissance mis en cause dans le processus morbide, qui jouent probablement un rôle important dans les manifestations gastro-intestinales de la sclérodermie. Le rôle des cytokines comme cible thérapeutique dans la sclérodermie constitue l'objet du présent examen.
Systemic sclerosis (SSc), or scleroderma, is a connective tissue disorder characterized by progressive fibrosis of the skin and internal organs, as well as prominent changes in the microvasculature (1). There are two main subsets of the disease, referred to as limited and diffuse SSc. Diffuse SSc is the more serious form, because it affects visceral organs as well as the skin. SSc has considerable significance for gastroenterologists, because the gastrointestinal (GI) tract is the most commonly involved visceral system, and is affected in up to $90 \%$ of SSc patients (2). While esophageal dysfunction is the earliest and most prevalent GI manifestation, the disease has been shown to affect virtually all parts of the GI tract $(2-4)$.

The disease is believed to progress in an organized fashion, beginning with a primary lesion of the autonomic nervous system before there is any physical damage to the smooth muscle (4). This often goes unnoticed by the patient. The initial neural insult is followed by smooth muscle atrophy, at which point GI symptoms generally become apparent. The final stage of the disease is the development of fibrosis leading to eventual loss of function (3). At this stage, the muscle is incapable of restoration and aggressive interventions may be required. Given the progressive fate of this disease, early diagnosis, accurate staging and appropriate treatment are important in delaying or preventing future complications. Unfortunately, GI involvement often goes unnoticed until complications have already arisen and, thus, the general therapeutic approach is to treat SSc manifestations as they arise (4). There are no effective treatments targeting the underlying disease process but understanding the factors that contribute to SSc pathology will enable the development of new therapies for this elusive and devastating disease.

\section{PATHOPHYSIOLOGY OF SSC}

The exact pathogenesis of SSc is unknown but there is increasing evidence supporting an immunogenic theory, including $\mathrm{T}$ cell and $\mathrm{B}$ cell abnormalities (5). Antifibroblast autoantibodies have recently been identified that may promote activation of fibroblasts toward a proinflammatory/proadhesive phenotype, a key process in SSc pathology (6). Circulating autoantibodies have become useful markers of disease subset (7) and reports suggest that the diffuse and limited forms of the disease may be characterized by distinct cytokine and T cell profiles (8).

The pathophysiology of SSc includes at least three components: inappropriate immune activation; vascular damage and tissue atrophy; and the development of fibrosis $(5,9)$. An activated immune system is the prominent feature of early disease, while propagation of the fibrotic phenotype prevails as the disease progresses (9). Disease stage and duration are important factors in determining appropriate therapeutic targets, with immunomodulation as the

Departments of ${ }^{1}$ Pharmacology and ${ }^{2}$ Medicine, Faculty of Medicine, Dalhousie University, Halifax, Nova Scotia

Correspondence: Dr TC Peterson, Department of Medicine, Tupper Medical Building, 11-C1, Dalhousie University, Halifax,

Nova Scotia B3H4H7. Telephone 902-494-2571, fax 902-494-1388, e-mail tcpmed@dal.ca

Received for publication March 3, 2003. Accepted October 30, 2003 
early goal followed by prevention or reversal of fibrosis in later stages. Cytokines are important therapeutic targets because of their role in immune activation, fibroblast proliferation and extracellular matrix (ECM) accumulation in SSc. Key cytokines in SSc include transforming growth factor beta (TGF- $\beta$ ), platelet derived growth factor (PDGF), connective tissue growth factor (CTGF), interleukins (IL) 4 and 6, and the chemokine monocyte chemoattractant protein-1 (MCP-1) $(10,11)$.

\section{TGF- $\beta$}

TGF- $\beta$ plays an important role in the pathogenesis of SSc (12), inducing the synthesis of several $\mathrm{ECM}$ proteins including type I collagen, and inhibiting matrix-degrading enzymes (13). TGF- $\beta$ is a potent chemoattractant for fibroblasts and stimulates the release of proinflammatory and profibrotic cytokines such as PDGF (14) and CTGF (12). TGF- $\beta$ plays a more prominent role in limited SSc than diffuse SSc (15) and its production is elevated in early SSc lesions before fibrosis has developed (16). Alterations in TGF- $\beta$ signaling, rather than elevated levels of TGF- $\beta$, are now proposed to contribute to SSc pathology because there is evidence of increased TGF- $\beta$ receptor levels on fibroblasts from certain SSc patients (17) and aberrant intracellular signaling components (18). Targeting specific components of the TGF- $\beta$ signaling pathway may have beneficial effects in SSc. Halofuginone is a novel inhibitor of collagen synthesis that has antifibrotic effects in two animal models of SSc $(19,20)$ and in human SSc patients (21). Halofuginone disrupts TGF- $\beta$ signaling (22) and inhibits COL1A2 promoter activity via a c-Jun-dependent mechanism (23).

\section{CTGF}

CTGF is a mitogen for endothelial cells and fibroblasts, that is induced by TGF- $\beta(11,12)$ and stimulates the production of ECM components including type I collagen (13). CTGF expression is significantly higher in skin fibroblasts, plasma and blister fluids from SSc patients compared with controls $(24,25)$. Whereas TGF- $\beta$ is detectable in certain prefibrotic lesions, CTGF is expressed in fibrotic SSc lesions (26) and correlates positively with the extent of fibrosis (27). Iloprost, a prostacyclin analogue with antifibrotic activity used in SSc patients, exerts its antifibrotic effects by inhibiting a specific cascade in the TGF- $\beta$ signaling pathway, which abolishes CTGF-induction by TGF- $\beta$ (28). CTGF is likely a downstream mediator of the profibrotic effects of TGF- $\beta$ and could be a useful target in SSc because inhibiting CTGF could reduce fibrosis while sparing the beneficial antiproliferative and immunosuppressive effects of TGF- $\beta$.

\section{PDGF}

PDGF is a potent mitogen for fibroblasts and is implicated in the pathogenesis of SSc and other fibrotic diseases (10). PDGF stimulates proliferation of myofibroblasts in nonconfluent cultures, while stimulating collagen synthesis in confluent monolayers (29). Because fibroproliferation and collagen synthesis are two key processes in SSc pathology, PDGF is a potential therapeutic target in this disease. PDGF and its receptors are detectable in biopsy samples and skin from SSc patients, with highest levels in areas of active disease $(10,30,31)$. PDGF acts synergistically with TGF- $\beta$ in SSc fibroblasts and is known to induce the production of IL-6, another cytokine implicated in SSc pathology (32).

Pentoxifylline (PTX) inhibited proliferation and collagen synthesis by cultured fibroblasts and myofibroblasts stimulated with PDGF $(29,33)$ and cultured SSc fibroblasts (34). It also prevented the development of liver fibrosis in an experimental model (35).
A recent study revealed that PTX interrupts PDGF-driven fibroproliferation by inhibiting PDGF-induced expression of c-jun (36). Antisense to c-jun also inhibited PDGF-induced fibroproliferation in this study. It was found that PTX specifically blocks the phosphorylation of c-Jun protein at serine residue 73 . These findings suggest that pentoxifylline has considerable potential as an antifibrotic agent in SSc.

\section{IL-4 AND IL-6}

IL-4 is a profibrotic cytokine that has been implicated in SSc (37) and like PDGF, it also stimulates proliferation and collagen synthesis by fibroblasts (38). High serum levels of IL-4 correlate with increased disease severity in SSc patients (37) and in the tightskin (TSK) mouse model of SSc (39). Fibroblasts from TSK mice show increased sensitivity to IL-4 and TGF- $\beta$ and synthesize excessive amounts of collagen (40). Neutralizing antibodies against IL-4 were reported to reduce skin fibrosis in these mice (41) while mice deficient in IL-4 did not develop the fibrotic skin phenotype (42). Amelioration of dermal fibrosis by anti-IL-4 treatment in TSK mice suggests that IL-4 is a contributing factor, but reports that transgenic mice overexpressing IL-4 do not develop SSc symptoms (43) indicate that IL-4 is not a causal agent in SSc.

IL-6 levels are elevated in serum from SSc patients and correlate positively with skin thickness, making it a useful serological indicator of skin fibrosis (44). IL-6 production by SSc fibroblasts is significantly increased (30-fold) compared with normal fibroblasts and may be the result of constitutive binding of nuclear factors to the IL-6 promoter (45). Treatment with a combination of iloprost and cyclosporin A for one year significantly decreased serum IL-6 levels and resulted in morphological and functional improvement in the esophagus, skin and microvasculature (46). Reduction of IL- 6 and IL-4 decreased fibrosis in the TSK mouse model of SSc, resulting in marked reduction in skin thickness and serum levels of antinuclear antibodies (47), suggesting that IL-6 should be considered as part of an anticytokine approach to the treatment of SSc.

\section{MCP-1}

MCP-1 is a chemokine involved in recruiting and activating immune cells during inflammation (48) and is expressed in SSc skin lesions by fibroblasts and infiltrating mononuclear cells (49). MCP-1 was elevated in serum from SSc patients where it correlated with the presence of pulmonary fibrosis (50). The increased expression of MCP-1 by SSc fibroblasts is thought to contribute to the presence of perivascular infiltrates of inflammatory cells in SSc patients, implicating a role in early processes leading to SSc lesions (51). This was supported in an experimental model of SSc, where MCP-1 was expressed before the development of any skin or lung fibrosis (52). Therapeutic strategies targeting MCP-1 may have beneficial effects in SSc, particularly in the early stages of disease development.

\section{CONCLUSION}

Scleroderma is a rare yet devastating disease that involves fibrosis of the skin and internal organs. The GI tract is the most commonly involved visceral system, and is affected in up to $90 \%$ of SSc patients. Esophageal dysfunction is typically the earliest presenting complication but the disease can attack any segment of the GI tract. The cytokines discussed here play a significant role in SSc. New therapies developed to block or suppress key cytokines will have tremendous potential for treating the frequent GI complications of SSc patients by targeting the underlying disease process. 


\section{REFERENCES}

1. Generini S, Fiori G, Moggi Pignone A, Matucci Cerinic M, Cagnoni M. Systemic sclerosis: A clinical overview. Adv Exp Biol Med (RheumaDerm) 1999;455:73-83.

2. Rose S, Young MA, Reynolds JC. Gastrointestinal manifestations of scleroderma. Gastro Clin North Am 1998;27:563-93.

3. Sjogren RW. Gastrointestinal motility disorders in scleroderma. Arthritis Rheum 1994;37:1265-82.

4. Lock G, Holstege A, Lang B, Scholmerich J. Gastrointestinal manifestations of progressive systemic sclerosis. Am J Gastroenterol 1997;92:763-71.

5. Sapadin AN, Esser AC, Fleischmajer R. Immunopathogenesis of scleroderma: Evolving concepts. Mt Sinai J Med 2001;68:233-42.

6. Chizzolini C, Raschi E, Rezzonico R, et al. Autoantibodies to fibroblasts induce a proadhesive and proinflammatory fibroblast phenotype in patients with systemic sclerosis. Arthritis Rheum 2002;46:1602-13.

7. Okano Y. Antinuclear antibodies in systemic sclerosis (scleroderma). Rheum Dis Clin North Am 1996;22:709-35.

8. Ingregnoli F, Trabattoni D, Saresella M, Fantini F, Clerici M. Distinct immune profiles characterize patients with diffuse or limited systemic sclerosis. Clin Immunol 2003;108:21-8.

9. Black CM. The treatment of scleroderma. Adv Exp Biol Med (RheumaDerm) 1999;455:271-7.

10. Fagundus MD, Leroy EC. Cytokines and systemic sclerosis. Clin Dermatol 1994;12:407-17.

11. Simms RW, Korn JH. Cytokine directed therapy in scleroderma: Rationale, current status, and the future. Curr Opin Rheumatol 2002;14:717-22.

12. Denton CP, Abraham DJ. Transforming growth factor- $\beta$ and connective tissue growth factor: Key cytokines in scleroderma pathogenesis. Curr Opin Rheumatol 2001;13:505-11.

13. Ghosh AK. Factors involved in the regulation of type I collagen gene expression: Implication in fibrosis. Exp Biol Med 2002;227:301-14.

14. Moses HL, Coffey RJ, Loef EB, Lyons RM, Keski-Oja J. Transforming growth factor beta regulation of cell proliferation. J Cell Biol 1987;5(Suppl):1-7.

15. Cotton SA, Herrick AL, Jayson MI, Freemont AJ. TGF- $\beta$ - A role in systemic sclerosis? J Pathol 1998;184:4-6.

16. Helman S, Cotton SA, Jayson MIV, Hoyland J, Herrick A, Freemont AJ. Microvascular abnormality and TGF- $\beta$ in systemic sclerosis skin. $\mathrm{Br}$ J Rheumatol 1997;36(Suppl 1):30(54A).

17. Yamane $K$, Ihn $H$, Kubo M, Tamaki K. Increased transcriptional activities of transforming growth factor $\beta$ receptors in scleroderma fibroblasts. Arthritis Rheum 2002;46:2421-8.

18. Dong C, Zhu S, Wang T, et al. Deficient smad7 expression: A putative molecular defect in scleroderma. Proc Natl Acad Sci USA 2002;99:3908-13.

19. Yamamoto T, Nishioka K. Analysis of the effect of halofuginone on bleomycin-induced fibrosis. Rheumatology 2002;41:594-6.

20. Levi-Schaffer F, Nagler A, Slavin Sknopov V, Pines M. Inhibition of collagen synthesis and changes in skin morphology in murine graft-versus-host disease and tight skin mice: Effect of halofuginone. J Clin Invest 1996;106:84-8.

21. Pines N, Snyder D, Yarkoni S, Nagler A. Halofuginone to treat fibrosis in chronic graft-versus-host disease and scleroderma. Biol Blood Marrow Transplant 2003;9:417-25.

22. McGaha TL, Phleps RG, Spiera H, Bona C. Halofuginone, an inhibitor of type I collagen synthesis and skin sclerosis, blocks TGF- $\beta$ mediated Smad3 activation in fibroblasts. J Invest Dermatol 2002;118:461-70.

23. McGaha TL, Kodera T, Spiera H, Stan AC, Pines M, Bona CA. Halofuginone inhibition of COL1A2 promoter activity via a c-jundependent mechanism. Arthritis Rheum 2002;46:2748-61.

24. Shi-wen X, Pennington D, Holmes A, et al. Autocrine overexpression of CTGF maintains fibrosis: RDA analysis of fibrosis genes in systemic sclerosis. Exp Cell Res 2000;259:213-24.

25. Stratton R, Shi-wen X, Martini G, et al. Iloprost suppresses connective tissue growth factor production in fibroblasts and in the skin of scleroderma patients. J Clin Invest 2001;108:241-50.

26. Igarashi A, Nashiro K, Kikuchi K, et al. Connective tissue growth factor gene expression in tissue sections from localized scleroderma, keloid, and other fibrotic skin disorders. J Invest Dermatol 1996;106:723-33

27. Igarashi A, Nashiro K, Kikuchi K, et al. Significant correlation between connective tissue growth factor gene expression and skin sclerosis in tissue sections from patients with scleroderma. J Invest Dermatol 1995;105:280-4.

28. Stratton R, Rajkumar V, Ponticos M, et al. Prostacyclin derivatives prevent the fibrotic response to TGF- $\beta$ by inhibiting the Ras/MEK/ERK pathway. FASEB J 2002;16:1949-51.
29. Isbrucker RA, Peterson TC. Platelet-derived growth factor and pentoxifylline modulation of collagen synthesis in myofibroblasts. Toxicol Appl Pharmacol 1998;149:120-6.

30. Zheng XY, Zhang JZ, Tu P, Ma SQ. Expression of platelet-derived growth factor B-chain and platelet-derived growth factor beta-receptor in fibroblasts of scleroderma. J Dermatol Sci 1998;18:90-7.

31. Klareskog L, Gustafsson R, Scheynius A, et al. Increased expression of plasma platelet-derived growth factor type $\beta$ receptors in systemic sclerosis. Arthritis Rheum 1990;33:1534-41.

32. Takemura H, Suzuki H, Fujisawa H, et al. Enhanced interleukin-6 production by cultured fibroblasts from patients with systemic sclerosis in response to platelet-derived growth factor. J Rheumatol 1998;25:1534-9.

33. Peterson TC, Isbrucker R, Hooper ML. In vitro effect of plateletderived growth factor on fibroproliferation and effect of cytokine antagonists. Immunopharmacology 1994;28:259-70.

34. Berman B, Duncan MR. Pentoxifylline inhibits the proliferation of human fibroblasts derived from keloid, scleroderma, and morphoea skin and their production of collagen, glycosaminoglycan, and fibronectin. Br J Dermatol 1990;123:339-46.

35. Peterson TC. Pentoxifylline prevents fibrosis in an animal model and inhibits platelet-derived growth factor-driven proliferation of fibroblasts. Hepatology 1993;17:486-93.

36. Peterson TC, Peterson MR, Robertson HA, During M, Dragunow M. Selective down-regulation of c-jun gene expression by pentoxifylline and c-jun anti-sense interrupts platelet-derived growth factor signaling: Pentoxifylline inhibits phosphorylation of c-Jun on serine 73. Mol Pharmacol 2002;61:1476-88.

37. Tsuji-Yamada J, Nakazawa M, Minami M, Sasaki T. Increased frequency of interleukin 4 producing CD4+ and CD8+ cells in peripheral blood from patients with systemic sclerosis. J Rheumatol 2001;28:1252-8.

38. Postlethwaite AE, Holness MA, Katai H, Raghow R. Human fibroblasts synthesize elevated levels of extracellular matrix proteins in response to interleukin-4. J Clin Invest 1992;90:1479-85.

39. Jimenez SA, Millan A, Bashey RI. Scleroderma-like alterations in collagen metabolism occurring in the TSK (tight skin) mouse. Arthritis Rheum 1984;27:180-5.

40. Makhluf HA, Stepniakowska J, Hoffman S, Smith E, LeRoy EC, Trojanowska M. IL-4 upregulates tenascin synthesis in scleroderma and healthy skin fibroblasts. J Invest Dermatol 1996;107:856-9.

41. Ong C, Wong C, Roberts CR, Teh HS, Jirik FR. Anti-IL-4 treatment prevents dermal collagen deposition in the tight-skin mouse model of scleroderma. Eur J Immunol 1998;28:2619-29.

42. Ong CJ, Ip S, Teh SJ, et al. A role for T helper 2 cells in mediating skin fibrosis in tight-skin mice. Cell Immunol 1999;196:60-8

43. Tepper RI, Levinson DA, Stanger BZ, Campos-Torres J, Abbas A, Leder P. IL-4 induces allergic-like inflammatory disease and alters $\mathrm{T}$ cell development in transgenic mice. Cell 1990;62:457-67.

44. Sato S, Hasegawa M, Takehara K. Serum levels of interleukin 6 and interleukin 10 correlate with total skin thickness score in patients with systemic sclerosis. J Dermatol Sci 2001;27:140-6.

45. Feghali CA, Bost KL, Boulware DW, Levy LS. Control of IL-6 expression and response to fibroblasts from patients with systemic sclerosis. Autoimmunity 1994;17:309-18.

46. Filaci G, Cutolo M, Scudeletti M, et al. Cyclosporin A and iloprost treatment of systemic sclerosis: Clinical results and interleukin-6 serum changes after 12 months of therapy. Rheumatology (Oxford) 1999;38:992-6.

47. Tsuji-Yamada J, Nakazaw M, Takahashi K, et al. Effect of IL-12 encoding plasmid administration on tight-skin mouse. Biochem Biophys Res Comm 2001;280:707-12.

48. Leonard EJ, Yoshimura T. Human monocyte chemoattractant protein-1 (MCP-1). Immunol Today 1999;11:97-101.

49. Yamamoto T, Eckes B, Hartmann K, Krieg T. Expression of monocyte chemoattractant protein-1 in the lesional skin of systemic sclerosis. J Dermatol Sci 2001;26:133-9.

50. Hasegawa M, Sato S, Takehara K. Augmented production of chemokines (monocyte chemotactic protein-1 (MCP-1), macrophage inflammatory protein-1 $\alpha$ (MIP-1 $\alpha)$ and MIP-1 $\beta)$ in patients with systemic sclerosis: MCP-1 and MIP- $1 \alpha$ may be involved in the development of pulmonary fibrosis. Clin Exp Immunol 1999;117:159-65.

51. Denton CP, Shi-Wen X, Sutton A, Abraham DJ, Black CM, Pearson JD. Scleroderma fibroblasts promote migration of mononuclear leucocytes across endothelial cell monolayers. Clin Exp Immunol 1998;114:293-300.

52. Zhang Y, McCormick LL, Desai SR, Wu C, Gilliam AC. Murine sclerodermatous graft-versus-host disease, a model for human scleroderma: Cutaneous cytokines, chemokines, and immune cell activation. J Immunol 2002;168:3088-98. 


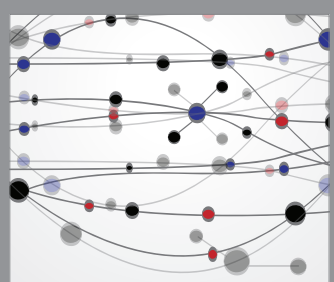

The Scientific World Journal
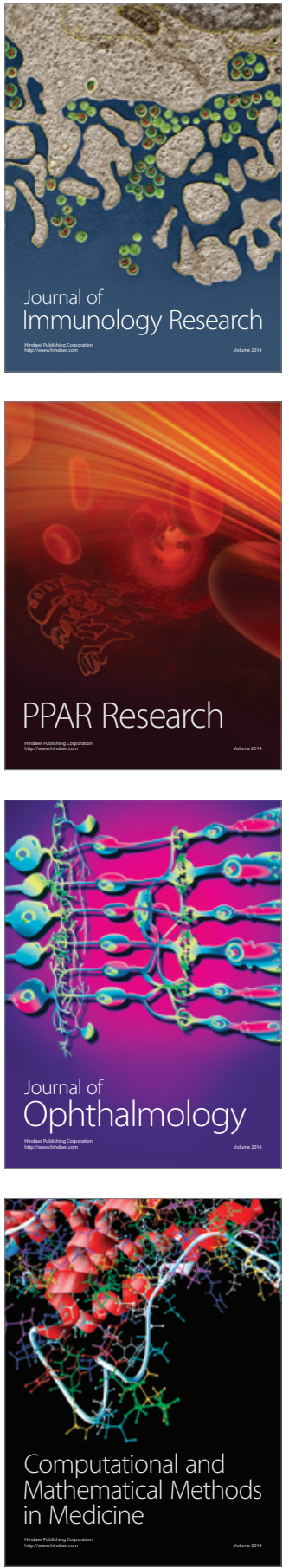

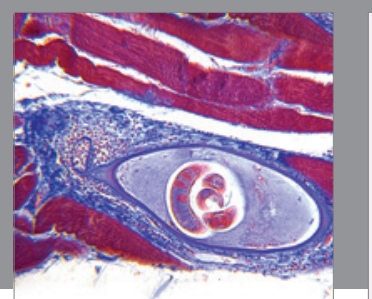

Gastroenterology Research and Practice

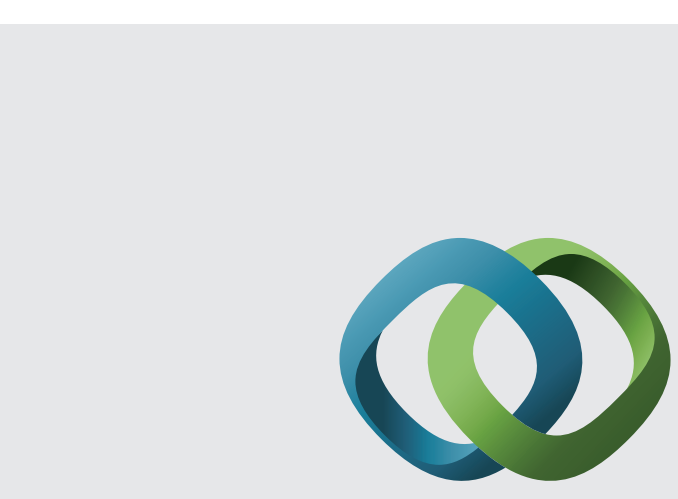

\section{Hindawi}

Submit your manuscripts at

http://www.hindawi.com
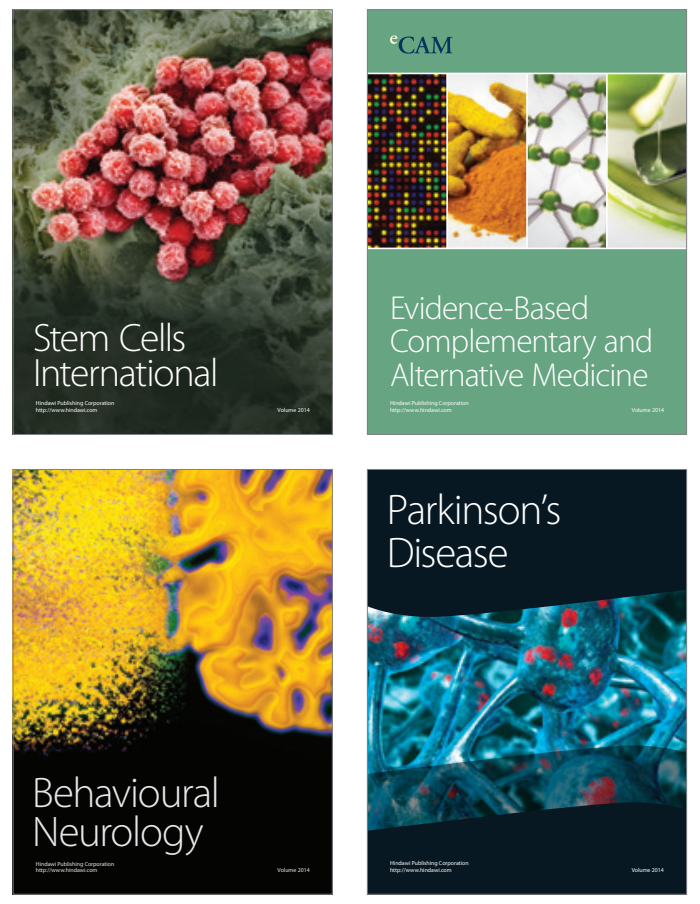
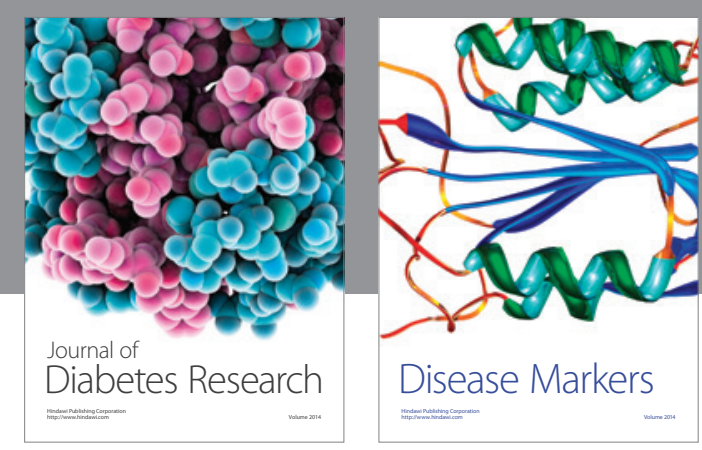

Disease Markers
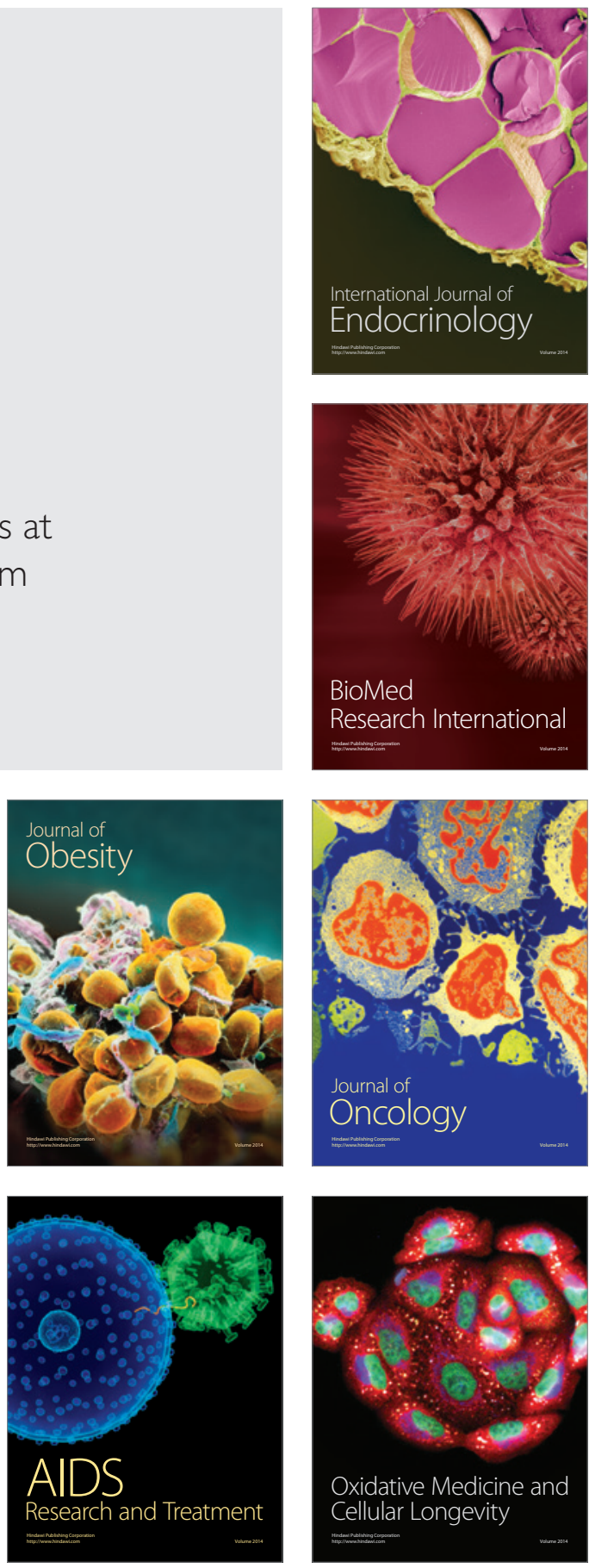